\title{
Pengaruh Persepsi, Motivasi, Self Efficacy, Pengaruh Orang Tua terhadap Minat Mahasiswa Jurusan Akuntansi sebagai Konsultan Pajak
}

\author{
*Novi Febriani, Tri Lestari, Siti Rosyafah \\ Prodi Manajemen Fakultas Ekonomi dan Bisnis \\ Universitas Bhayangkara Surabaya, Indonesia
}

DOI: 10.46821/ekobis.v2i1.209

\begin{abstract}
ABSTRAK
Penelitian ini bertujuan untuk mengetahui pengaruh presepsi, motivasi, self efficacy dan pengaruh orang tua terhadap minat mahasiswa jurusan akuntansi sebagai konsultan pajak. Dalam hal ini mahasiswa, nantinya akan memutuskan apa yang akan mereka lakukan setelah menyelesaikan program studinya. Lapangan kerja untuk mereka yang ingin berkarir sebagai konsultan pajak masih terbuka lebar. Dan wajib pajak setiap tahun selalu bertambah. Penelitian ini dilaksanakan di Fakultas Ekonomi dan Bisnis Universitas Bhayangkara Surabaya. Hasil analisis menyebutkan bahwa faktor-faktor seperti presepsi, motivasi, self efficacy, dan pengaruh orang tua dapat menumbuhkan minat mahasiswa untuk berkarir sebagai konsultan pajak. Hal ini dikarenakan dapat dilihat dari penelitianpenelitian sebelumnya menyatakan bahwa faktor-faktor tersebut besar kemungkinan akan menumbuhkan minat berkarir sebagai konsultan pajak untuk mahasiswa akuntansi.
\end{abstract}

Kata Kunci: Persepsi, Motivasi, Self Efficacy, Minat, Konsutan Pajak

\begin{abstract}
This study aims to determine the effect of perceptions, motivation, self-efficacy and the influence of parents on the interest of accounting students as tax consultants. In this case, students will decide what to do after completing their study program. Job opportunities for those who want a career as tax consultants are still wide open. And taxpayers are always increasing every year. This research was conducted at the Faculty of Economics and Business, Bhayangkara University Surabaya. The results of the analysis state that factors such as perception, motivation, self-efficacy, and parental influence can foster student interest in a career as a tax consultant. This is because it can be seen from previous studies that these factors are likely to generate interest in a career as a tax consultant for accounting students.
\end{abstract}

Keywords: Perception, Motivation, Self Efficacy, Interests, Tax Consultant

\section{PENDAHULUAN}

Mahasiswa sebagai generasi penerus dan pelurus bangsa seharusnya sudah dapat menentukan apa yang mereka inginkan setelah melewati masa perkuliahan. Profesi yang menarik ditekuni adalah profesi dibidang perpajakan. Lulusan akuntansi dapat memilih berkarir di bidang perpajakan rasionalnya karena sejalan dengan ilmu yang juga dibekali dalam perkuliahan di jurusan akuntansi yaitu terkait dengan ilmu perpajakan. Sehingga tidak menutup kemungkinan lulusan 
mahasiswa akuntansi untuk dapat berkarir di perpajakan. Salah satu pilihan karir di bidang perpajakan yang dapat digeluti yaitu menjadi konsultan pajak. Masih rendahnya minat mahasiswa dalam berkarir sebagai konsultan pajak itu sendiri karena banyak resiko yang harus ditangani oleh tenaga konsultan pajak membuat kesadaran akan pemilihan karir dalam bidang ini masih rendah, tanpa disadari bahwanya karir dalam bidang konsultan pajak ini memberikan perluang dan banyak kesempatan yang ditawarkan, karena selisih antara jumlah wajib pajak dan tenaga konsultan pajak sangat jauh hingga mengakibatkan adanya kesenjangan.

\section{TINJAUAN PUSTAKA}

\section{Persepsi}

Menurut Slameto (2010:102) menyatakan bahwa persepsi adalah proses yang menyangkut masuknya pesan atau informasi kedalam otak manusia, melalui persepsi manusia terus menerus mengadakan hubungan dengan lingkungannya. Hubungan ini dilakukan lewat inderanya, yaitu indera pengelihat, pendengar, peraba, perasa, dan pencium.

\section{Self Efficacy}

Self efficacy merupakan suatu keyakinan atau kepercayaan diri individu mengenai kemampuannya untuk mengorganisasi, melakukan suatu tugas, mencapai suatu tujuan, menghasilkan sesuatu dan mengimplementasi tindakan untuk mencapai kecakapan tertentu.

\section{Pengaruh Orang Tua}

Menurut Lestari (2012:153) "peran orang tua merupakan cara yang digunakan oleh orang tua berkaitan dengan pandangan mengenai tugas yang harus dijalankan dalam mengasuh anak". Hadi (2016:102) menyatakan bahwa "orang tua memiliki kewajiban dan tanggung jawab untuk mengasuh, memelihara, mendidik, dan melindungi anak".

\section{Minat}

Minat berkaitan erat dengan motivasi seseorang, sesuatu yang dipelajari dan apa yang dilihat serta digemari. Minat juga dapat berubah-ubah tergantung pada kebutuhan, pengalaman, dan mode yang sedang trend, bukan bawaan sejak lahir.

\section{METODE PENELITIAN}

\section{Pendekatan Penelitian}

Pendekatan penelitian ini menggunakan penedekatan kuantitatif karena dalam penelitian ini menggunakan perhitungan statistik, maka pendekatan penelitian ini adalah pendekatan kuantitatif dengan menggunakan alat uji regresi berganda. Menurut Sugiyono (2013: 13), metode penelitian kuantitatif dapat diartikan sebagai metode penelitian yang berlandaskan pada filsafat positivisme, yang digunakan untuk meneliti pada populasi atau sampel tertentu, teknik pengambilan sampel yang pada umumnya dilakukan secara random, pengumpulan data menggunakan instrument penelitian, analisis data bersifat kuantitatif atau statistik dengan tujuan untuk menguji hipotesis yang telah ditetapkan. 


\section{Jenis dan Sumber Data \\ Jenis Data \\ Berdasarkan jenisnya, data yang digunakan dalam penelitian ini adalah data kuantitatif. Pada penelitian ini data kuantitatif yang digunakan adalah data kuesioner yang dilakukan terhadap responden perokok yang diukur dengan menggunakan skala pengukuran. Teknik yang digunakan dalam penelitian ini dimana peneliti menggunakan pemberian skor dalam kuesioner adalah dengan menggunakan skala interval (likert) lima tingkat.}

\section{Sumber Data}

Berdasarkan sumbernya, penelitian ini menggunakan data primer, dimana data yang diperoleh berasal dari sumber asli. Menurut Sugiyono (2013: 137) data primer adalah data yang diperoleh secara langsung yang berhubungan dengan penelitian. Data primer yang digunakan dalam penelitian ini diperoleh dari responden mahasiswa Universitas Bhayangkara Surabaya.

\section{Teknik Pengumpulan Data}

Metode Pengumpulan data yang digunakan dalam penelitian ini adalah dengan cara Survei Kuesioner, dokumentasi dan studi pustaka. Skala instrumen pengumpulan data penelitian menggunakan skala Likert.

Pada penelitian ini cara yang digunakan oleh peneliti dalam pengambilan sampel menggunakan rumus Slovin yakni sebagai berikut:

$\mathrm{n}=79,4$ dibulatkan sehingga $79 \mathrm{n}=79$

Keterangan:

n : ukuran sampel

$\mathrm{N} \quad$ : ukuran populasi

$e \quad$ :persentase kelonggaran ketidaktelitian karena kesalahan pengambilan

$$
n=\frac{N}{1+N \cdot e^{2}}=\frac{392}{1+392 \cdot(0,1)^{2}}=79,4=79 \text { Responden }
$$

\section{HASIL ANALISIS DAN PEMBAHASAN \\ Teknik Analisis Data dan Uji Hipotesis \\ Uji Validitas Data}

Uji validitas digunakan untuk mengukur sah atau valid tidaknya suatu kuesioner. Apabila nilai sig.(2-tailed) kurang dari 0.05 maka data dinyatakan valid (Sugiarto, 2017:220).

\section{Persepsi}

Pada Tabel 1 dapat ditunjukkan bahwa semua item pertanyaan untuk variabel persepsi mempunyai nilai signifikansi lebih kecil dari 0,05 sehingga dinyatakan valid.

\section{Motivasi}

Tabel 2 dapat ditunjukkan bahwa semua item pertanyaan untuk variabel motivasi mempunyai nilai signifikansi lebih kecil dari 0,05 sehingga dinyatakan valid. 


\section{Self Efficacy}

Tabel 3 dapat ditunjukkan bahwa semua item pertanyaan untuk variabel self efficacy mempunyai nilai signifikansi lebih kecil dari 0,05 sehingga dinyatakan valid.

\section{Pengaruh Orang Tua}

Tabel 4 menunjukkan bahwa semua item pertanyaan untuk variabel pengaruh orang tua mempunyai nilai signifikansi lebih kecil dari 0,05 sehingga dinyatakan valid.

\section{Pilihan Berkarir sebagai Konsultan Pajak}

Tabel 5 dapat ditunjukkan bahwa semua item pertanyaan untuk variabel pilihan berkarir sebagai konsultan pajak mempunyai nilai signifikansi lebih kecil dari 0,05 sehingga dinyatakan valid.

\section{Uji Reliabilitas Data}

Uji reliabilitas digunakan untuk mengukur konsistensi jawaban responden di dalam kuesioner. Apabila nilai Cronbanch's Alpha di atas 0,60 maka suatu kuesioner dapat dikatakan reliabel.

Tabel 6 dapat ditunjukkan bahwa nilai Cronbanch's Alpha variabel persepsi sebesar 0.637, motivasi sebesar 0.695, self efficacy sebesar 0.630, pengaruh orang tua sebesar 0.770 , dan pilihan berkarir sebagai konsultan pajak sebesar 0.748 .

\section{Uji t}

Uji t digunakan untuk menentukan apakah variabel independent (persepsi, motivasi, self efficacy, dan pengaruh orang tua) secara individual atau parsial berpengaruh terhadap variabel dependen (pilihan berkarir sebagai konsultan pajak). Hipotesis yang untuk penelitian ini sebagai berikut:

H1 = Persepsi Mahasiswa berpengaruh Terhadap Pilihan Berkarir Dibidang Perpajakan.

H2 = Motivasi Mahasiswa berpengaruh Terhadap Pilihan Berkarir Dibidang Perpajakan.

H3 = Self Efficacy Mahasiswa Berpengaruh Positif Terhadap Pilihan Berkarir Dibidang Perpajakan.

H4 = Pengaruh Orang Tua berpengaruh Terhadap Pilihan Berkarir Dibidang Perpajakan.

Tabel 1

Hasil Uji Validitas Variabel Persepsi

\begin{tabular}{ccccc}
\hline No & Pertanyaan & Sig. (2-tailed) & Ketentuan & Keterangan \\
\hline 1 & X1.1 & .000 & $<0,05$ & Valid \\
2 & X1.2 & .000 & $<0,05$ & Valid \\
3 & X1.3 & .000 & $<0,05$ & Valid \\
4 & X1.4 & .000 & $<0,05$ & Valid \\
5 & X1.5 & .000 & $<0,05$ & Valid \\
\hline
\end{tabular}

Sumber: Data Diolah (2021) 
Tabel 2

Hasil Uji Validitas Variabel Motivasi

\begin{tabular}{ccccc}
\hline No & Pertanyaan & Sig. (2-tailed) & Ketentuan & Keterangan \\
\hline 1 & X2.1 & .000 & $<0,05$ & Valid \\
2 & X2.2 & .000 & $<0,05$ & Valid \\
3 & X2.3 & .000 & $<0,05$ & Valid \\
4 & X2.4 & .000 & $<0,05$ & Valid \\
5 & X2.5 & .000 & $<0,05$ & Valid \\
\hline
\end{tabular}

Sumber: Data Diolah (2021)

Tabel 3

Hasil Uji Validitas Variabel Self Efficacy

\begin{tabular}{ccccc}
\hline No & Pertanyaan & Sig. (2-tailed) & Ketentuan & Keterangan \\
\hline 1 & X1.1 & .000 & $<0,05$ & Valid \\
2 & X1.2 & .000 & $<0,05$ & Valid \\
3 & X1.3 & .000 & $<0,05$ & Valid \\
4 & X1.4 & .000 & $<0,05$ & Valid \\
5 & X1.5 & .000 & $<0,05$ & Valid \\
\hline
\end{tabular}

Sumber: Data Diolah (2021)

Tabel 4

Hasil Uji Validitas Variabel Pengaruh Orang Tua

\begin{tabular}{ccccc}
\hline No & Pertanyaan & Sig. (2-tailed) & Ketentuan & Keterangan \\
\hline 1 & X1.1 & .000 & $<0,05$ & Valid \\
2 & X1.2 & .000 & $<0,05$ & Valid \\
3 & X1.3 & .000 & $<0,05$ & Valid \\
4 & X1.4 & .000 & $<0,05$ & Valid \\
\hline
\end{tabular}

Sumber: Data Diolah (2021)

Tabel 6

Hasil Uji Reliabilitas

\begin{tabular}{clccc}
\hline No & \multicolumn{1}{c}{ Variabel } & Cronbanch's Alpha & Ketentuan & Keterangan \\
\hline 1 & Persepsi (X1) & .637 & $>0,60$ & Reliabel \\
2 & Motivasi (X2) & .695 & $>0,60$ & Reliabel \\
3 & Self Efficacy (X3) & .630 & $>0,60$ & Reliabel \\
4 & Pengaruh Orang Tua (X4) & .770 & $>0,60$ & Reliabel \\
5 & Pilihan Berkarir sebagai & .748 & $>0,60$ & Reliabel \\
\hline & Konsultan Pajak (Y) & & & \\
\hline
\end{tabular}

Sumber: Data Diolah (2021)

Tabel 7

Uji Parsial (Uji T)

\begin{tabular}{ccc}
\hline Model & Unstandardized Coefficients B & Sig \\
\hline X1 & .234 & 0.009 \\
X2 & .543 & 0.000 \\
X3 & .465 & 0.000 \\
X4 & .146 & 0.014 \\
\hline
\end{tabular}

Sumber: Data Diolah (2021)

Kriteria Pengambilan Keputusan 
a. Jika nilai signifikansi $(\mathrm{P})<0,05$ maka seluruh variabel independen berpengaruh secara simultan terhadap variabel dependen.

b. Jika nilai signifikansi $(\mathrm{P}) \geq 0,05$ maka seluruh variabel independen tidak berpengaruh secara simultan terhadap variabel dependen.

Berdasarkan tabel 7 dapat dijelaskan bahwa:

1. Pengaruh persepsi terhadap pilihan berkarir dibidang perpajakan Berdasarkan tabel 7, nilai signifikansi variabel persepsi (X1) adalah sebesar 0,009 atau kurang dari 0,05 sehingga dapat disimpulkan bahwa H1 diterima.

2. Pengaruh motivasi terhadap pilihan berkarir dibidang perpajakan

Nilai signifikansi variabel motivasi (X2) adalah sebesar 0,000 atau lebih kecil dari 0,05 sehingga dapat disimpulkan bahwa $\mathrm{H} 2$ diterima.

3. Pengaruh Self Efficacy terhadap pilihan berkarir dibidang perpajakan

Nilai signifikansi variabel self efficacy (X3) adalah sebesar 0,000 atau lebih kecil dari 0,05 sehingga dapat disimpulkan bahwa $\mathrm{H} 3$ diterima.

4. Pengaruh Orang Tua terhadap pilihan berkarir dibidang perpajakan Nilai signifikansi variabel pengaruh orang tua (X4) adalah sebesar 0,014 atau lebih kecil dari 0,05 sehingga dapat disimpulkan bahwa H4 diterima.

\section{SIMPULAN}

Berdasarkan hasil pengujian dan pembahasan pada bab sebelumnya, maka peneliti dapat menarik beberapa kesimpulan diantaranya adalah: (1) Varibel Persepsi (X1) berpengaruh secara parsial terhadap pilihan berkarir sebagai konsultan pajak diperoleh $\mathrm{t}$ hitung sebesar 2,670 > 1.665 dengan tingkat signifikan 0.009. Variabel motivasi (X2) berpengaruh terhadap pilihan berkarir sebagai konsultan pajak diperoleh $\mathrm{t}$ hitung sebesar 6.336 dengan tingkat signifikan 0.000. Variabel self efficacy (X3) berpengaruh terhadap pilihan berkarir sebagai konsultan pajak diperoleh t hitung sebesar 5.217 dengan tingkat signifikan 0.000. Variabel pengaruh orang tua (X4) berpengaruh terhadap pilihan berkarir sebagai konsultan pajak diperoleh t hitung sebesar 2.511 dengan tingkat signifikan 0.014. (2) Variabel persepsi, motivasi, self efficacy, dan pengaruh orang tua secara Bersamasama atau simultan berpengaruh terhadap pilihan berkarir sebagai konsultan pajak diperoleh $\mathrm{F}$ hitung lebih besar dari $\mathrm{F}$ tabel $(21.841>1.76)$ dengan nilai sig. sebesar 0.000 . (3) Variabel independent yang dominan berpengaruh terhadap variabel pilihan berkarir sebagai konsultan pajak adalah variabel motivasi dengan nilai Standardized Coefficient Beta sebesar 0.444, dibandingkan dengan variabel self efficacy sebesar 0.358 , persepsi sebesar 0.162, dan yang terakhir pengaruh orang tua sebesar 0.095. Saran secara parsial menunjukkan bahwa variabel persepsi dan pengaruh orang tua memiliki nilai pengaruh lebih kecil dibandingkan variabel motivasi dan self efficacy. Untuk menumbuhkan persepsi tiap mahasiswa sebaiknya dari kampus memberikan kegiatan khusus seperti pelatihan skill, praktek secara langsung di kantor pajak maupun konsultan pajak sehingga mahasiswa dapat menggambarkan dengan jelas bagaimana berkarir dibidang perpajakan. Saran untuk variabel persepsi dan pengaruh orang tua ketika bersama-sama atau secara simultan dengan motivasi dan self efficacy memiliki kontribusi yang kuat, artinya motivasi dan self efficacy memberikan dukungan terhadap pilihan berkarir sebagai konsultan pajak. Maka disarankan oleh peneliti bagi pihak kampus untuk meningkatkan aspek persepsi mulai dari dini, sehingga hal ini juga akan pengaruh ke aspek orang tua, 
supaya ketika memasuki semester akhir mahasiswa sudah siap dan matang dengan pilihan berkarirnya. Saran variabel yang dominan terhadap pilihan berkarir sebagai konsultan pajak adalah motivasi, diharapkan kampus dapat lebih meningkatkan motivasi tiap- tiap mahasiswa sehingga dapat mempengaruhi indicator-indikator yang lainnya. Sedangkan untuk variabel persepsi, self efficacy, dan pengaruh orang tua harus dapat lebih meningkatkan lagi indicator-indikator tersebut agar variabel tersebut lebih besar pengaruhnya terhadap pilihan berkarir sebagai konsultan pajak.

\section{DAFTAR PUSTAKA}

Adyagarini dkk., (2020) pengaruh motivasi, self efficacy, dan Pemahaman Pada Peraturan Menteri Keuangan Nomor 111/PMK.03/2014 terhadap minat berkarir mahasiswa akuntansi sebagai Konsultan Pajak. Jurnal ekonomi volume 9 nomor 1.

Abraham H. Maslow. (2013). Motivasi dan Kepribadian (Teori Motivasi dengan Pendekatan Hierarki Kebutuhan Manusia). PT. PBP, Jakarta.

Aji, Tri Susilo Wahyu,.Pratolo, Suryo. 2018. Pengaruh Politik Dinasti dan Sistem Pengendalian Internal Terhadap Kinerja Pemerintah Daerah dengan Akuntabilitas Pelaporan Sebagai Variabel Pemediasi: Studi Empiris Pada Pemerintah Daerah Di Indonesia Tahun 2012-2015. Jurnal Reviw Akuntansi dan Bisnis Indonesia. Vol 2, No. 2.

Damayanti (2017) Pengaruh persepsi, self efficacy, pertimbangan pasar kerja, nilai nilai social dan pengaruh orang tua terhadap minat mahasiswa jurusan akuntansi untuk berkarir sebagai konsultan pajak. Jurnal ekonomi volume 1 nomor 2.

Damayanti (2017), pengaruh persepsi dan motivasi terhadap minat mahasiswa program srudi perpajakan untuk berkarir sebagai konsultan pajak. Universitas Brawijaya.

Dayshandi, Dody. 2014. Pengaruh Persepsi dan Motivasi terhadap Minat Mahasiswa Program Studi Perpajakan untuk Berkarir di Bidang Perpajakan.Skripsi Universitas Brawijaya, Malang.

Feist, Jess dan Gregory J. Feist. 2011. Teori Kepribadian (Theories of Personality). Jakarta: Salemba Humanika.

Ghozali, H. I. (2011) Analisis Multivariate Lanjutan dengan Program SPSS. Semarang: Badan Penerbit Universitas Diponegoro.

Lestari, Sri. (2012). Psikologi Keluarga: Penanaman Nilai dan Penanganan Konflik Dalam Keluarga. Jakarta: Kencana.

Mulianto, S. F., \&Mangoting, Y. (2014). Faktor-faktor yang Mempengaruhi Pilihan Karir Mahasiswa Akuntansi sebagai Konsultan Pajak. Tax\&Accounting Review, 4 (2).

Nazaruddin, I. and Basuki, A. T. (2015) Analisis Statistik Dengan SPSS. Yogyakarta: Danisa Media.

Ormroad, Jeanne Ellis. 2012. Psikologi Pendidikan. Jilid 2. Jakarta: Penerbit Erlangga 
Ekobis: Jurnal Ekonomi \& Bisnis

Vol. 2 No. 12021

Novi Febriani dkk., Pengaruh Persepsi, Motivasi, Self

Prihatini, P. A., \& Rachmawati, N. A. (2020). Pengaruh Motivasi, Efektivitas Pembelajaran Mata Kuliah Perpajakan Dan Kesempatan Kerja Di Bidang Perpajakan Terhadap Minat Mahasiswa Akuntansi Dalam Berkarir Di Bidang Perpajakan. E-Prosiding Akuntansi, 2 (1).

Slameto. 2010. Belajar dan faktor-faktor yang Mempengaruhinya. Jakarta: PT. Rineka Cipta. Ghozali, Imam. 2014. Ekonometrika : Teori, Konsep dan Aplikasi dengan IBM SPSS 22. Badan Penerbit Universitas Diponegoro.

Sugiarto. Metode Penelitian Bisnis. 2017. Penerbit Andi. 